\title{
EXPRESSION OF iNOS, COX-2 AND VEGF IN \\ CANINE MAMMARY TUMOURS AND NON-NEOPLASTIC MAMMARY GLANDS: ASSOCIATION WITH CLINICOPATHOLOGICAL FEATURES AND TUMOUR GRADE
}

\author{
Elvan ANAdol ${ }^{1 *}$, Atiye Seda YAR SAGLAm ${ }^{2}$, Nilgun GUltiKeN ${ }^{3}$, Kubra KARAKAs $^{4}$, \\ Eray ALCIGIR ${ }^{5}$, Hasan ALKAN ${ }^{6}$ and Halit KANCA ${ }^{4}$ \\ ${ }^{1}$ Gazi University Laboratory, Animal Breeding and Experimental Research Centre and \\ ${ }^{2}$ Department of Medical Biology and Genetics, Faculty of Medicine, Gazi University, \\ Besevler, Ankara, Turkey; ${ }^{3}$ Department of Obstetrics and Gynaecology, Faculty of \\ Veterinary Medicine, Ondokuz Mayis University, Kurupelit, Samsun, Turkey; \\ ${ }^{4}$ Department of Obstetrics and Gynaecology and ${ }^{5}$ Department of Pathology, Faculty of \\ Veterinary Medicine, Ankara University, Diskapi, Ankara, Turkey; ${ }^{6}$ Department of \\ Obstetrics and Gynaecology, Faculty of Veterinary Medicine, Selcuk University, Konya, \\ Turkey
}

(Received 31 October 2016; accepted 4 April 2017)

The aim of the present study was to investigate the relationship between the expression of iNOS, COX-2 and VEGF mRNA levels and malignancy degree in canine malignant mammary tumours. Thirty-five bitches presented with the complaint of mammary masses, aged 6-10 years and representing different breeds, were used. The expressions of iNOS, COX-2 and VEGF mRNA levels were significantly higher in both benign and malignant tumours than in the adjacent nonneoplastic mammary glands $(\mathrm{P}<0.05)$. The iNOS, COX-2 and VEGF mRNA expression levels of grade 2 tumours were higher than those of grade 1 tumours; however, the highest expression levels were detected in grade 3 tumours. Thus, increased iNOS, COX-2 and VEGF gene mRNA levels were found to be related with the histological grade of malignancy in dogs with mammary tumours. VEGF

Key words: Canine mammary tumour, gene expression, iNOS, COX-2,

Mammary tumours are the most common neoplasms in the female dog (Johnston et al., 2001), and both benign and malignant tumours are diagnosed with equal frequency (Moulton, 1990). Prognostic factors for canine mammary tumour (CMT) are related to its malignant histological characteristics. According to the criteria, the therapy dose and the animal's survival are determined on the basis of predictive factors such as metastasis (Cianfrocca and Goldstein, 2004; Karayannopoulou et al., 2005).

\footnotetext{
"Corresponding author; E-mail: elvanadol@yahoo.com; Phone: 0090 (312) 202-4701
} 
Cyclooxygenases, especially COX-2, are implicated in tumour development and progression in human breast cancer (Howe, 2007). Similarly, the expression of COX-2 was demonstrated to be more frequent and more intense in malignant CMT than in benign tumours, suggesting its role in tumourigenesis (Dore et al., 2003). Additionally, a correlation was shown between COX-2 expression and more aggressive tumour phenotype (Guimaraes et al., 2014). It has been noticed that COX-2 may play a direct role in tumour cell growth through an antiapoptotic pathway and thus regulate tumour expansion indirectly in humans (Williams et al., 1999).

Neoplastic cells undergo genetic changes and acquire the ability to create their capillary blood supply in order to provide nourishment and oxygen for new cell growth, thus resulting in larger tumours (Villalobos and Kaplan, 2007). Vascular endothelial growth factor (VEGF) is the most important tumour angiogenesis factor which stimulates endothelial cell proliferation, leads to the formation of new blood vessels and regulates vascular permeability (Restucci et al., 2002; Queiroga et al., 2010). Furthermore, it has been determined that VEGF secretion in the stromal cells of tumours is caused by prostaglandins (Bing et al., 2001). COX-2 leads to tumour progression through the level of invasion, angiogenesis, metastasis and the inhibition of apoptosis (Heller et al., 2005). In addition, it has been shown that increased COX-2 expression was not significantly correlated with elevated VEGF expression as well as age, histologic type and tumour size in canine invasive mammary carcinomas (Millanta et al., 2006), whereas its expression was significantly correlated with poorer prognosis (Queiroga et al., 2010) and histological type of CMTs (Queiroga et al., 2011).

Nitric oxide (NO) is produced from L-arginine by nitric oxide synthases (NOS) such as neuronal NOS, endothelial NOS (eNOS) and inducible NOS (iNOS) (Förstermann et al., 1994). Endothelial NOS and neuronal NOS are expressed fundamentally in neurons and endothelial cells where their activation depends on calcium and calmodulin, whereas iNOS is expressed in macrophages, neutrophils, hepatocytes, cardiac myocytes, chondrocytes and various neoplastic diseases (Knowles and Moncada, 1994; Thomsen et al., 1995; Lechner et al., 2005). The role of NO in tumour cell apoptosis and survival depends on the cell type, the concentration and the time of cellular exposure to NO. Accordingly, the induction of apoptosis requires high levels of NO, particularly produced in the presence of iNOS (Lala and Chakraborty, 2001). Several studies have shown that the expression of iNOS in mammary tumours is correlated with angiogenesis and degree of malignancy in cats and humans (Vakkala et al., 2000; Islam et al., 2012). Islam et al. (2012) suggested that iNOS might be an immunohistochemical marker to detect the degree of malignancy in feline mammary carcinoma.

The aim of the present study was to investigate the relationship between the expression of iNOS, COX-2 and VEGF mRNA levels and the degree of malignancy in canine malignant mammary tumours, and to compare these expres- 
sions with those in clinically healthy mammary glands on the same mammary chain. To the best of our knowledge, this is the first study on the relationship between the expression of iNOS and malignancy degree in canine malignant mammary tumours.

\section{Materials and methods}

\section{Animals}

A total of 35 bitches (aged 6-10 years and representing different breeds) brought to the Clinic of Obstetrics and Gynaecology, Veterinary Faculty of the University of Ankara and University of Ondokuz Mayis with the complaint of mammary masses were used in the study. Animals with distant metastases and suspected inflammatory mammary carcinomas were not included. The surgical techniques included regional mastectomy as well as unilateral or bilateral complete mastectomy depending on the clinical stage and the number of tumours in the mammary gland chain. Malignant tumours were compared with adjacent non-neoplastic mammary glands of the dogs $(\mathrm{NMGs})(\mathrm{n}=8)$. The study was performed according to the principles outlined in Decision No. 2014/8 of the Ethics Committee of Animal Research of Turkey.

\section{Clinical and histopathological analysis}

Before starting the study, a complete physical examination was done for all animals. All mammary glands and regional lymph nodes (axillary and inguinal) were examined. Thoracic radiographs (right and left lateral, ventrodorsal) were taken and abdominal ultrasonographic examination was performed to determine the presence of metastasis. In addition, the number of tumours per animal, location, adherence to skin, adherence to underlying tissues, and tumour ulceration were recorded. The date of first presentation and the growth rate of the tumours (defined as slow, medium or fast) were also recorded based upon the history (Perez Alenza et al., 1997; Queiroga et al., 2005).

Mammary tissues were fixed in 10\% formalin solution, embedded in paraffin, and then 5- $\mu \mathrm{m}$ histological sections were made and stained with haematoxylin and eosin (HE). Tumours were classified by size (in centimetres; wide-largehigh as diameter), according to the World Health Organization Clinical Staging System TNM (Owen, 1980), as $\mathrm{T}_{1}(<3 \mathrm{~cm}), \mathrm{T}_{2}(3-5 \mathrm{~cm})$ and $\mathrm{T}_{3}(>5 \mathrm{~cm})$. In cases of multiple tumours, the largest one was used as the basis for classification.

Histological diagnosis was made on the basis of Goldschmidt's classification updated in recent years for CMTs as described by Goldschmidt et al. (2011). Histological grading of mammary tumours was performed according to the Nottingham grading system, which belongs to the Elston-Ellis modification of the original Scarff-Bloom-Richardson (SBR) grading system and is popularly known 
as the contemporary European Breast Cancer Grading System. This system is based on three morphological features: tubule formation, mitotic index and nuclear pleomorphism (Simpson et al., 2000). Scoring was obtained by screening 10 microscopic areas at $\times 400$ magnification (High Power Field) at the periphery of the tumour. Up to 9 mitoses per 10 fields were scored 1 point, 10-19 mitoses 2 points, and 20 or more mitoses 3 points. At the same time, tubule formation was evaluated as follows: majority of the tumour $(>75 \%)$, moderate degree (10$75 \%)$ and little or none $(<10 \%)$. Depending on the nuclear polymorphism, the cell characteristics were scored as follows: small regular uniform cells: 1 point; moderate nuclear size and variation: 2 points; marked nuclear variation: 3 points. Overall, Grade $1\left(\mathrm{G}_{1}\right)$ represented well-differentiated tumours of 3-5 points, Grade $2\left(\mathrm{G}_{2}\right)$ moderately differentiated tumours of 6-7 points, and Grade $3\left(\mathrm{G}_{3}\right)$ poorly differentiated tumours of 8-9 points (Elston and Ellis, 1998; Simpson et al., 2000). Additionally, in the differentiation of benign and malignant mammary tumours necrosis, invasion to periphery of tumour and lymphatics, and metastasis to regional lymph node were considered.

\section{Total RNA isolation and reverse transcriptase (RT) reaction}

Total RNA was isolated from the mammary tissue samples of 35 bitches using Trizol reagent (peqGOLD TriFastTM, Peqlab, Erlangen, Germany) and subsequently treated with RNase-free DNase I recombinant to prevent genomic DNA contaminations (DNase I; Roche Diagnostics, Germany) according to the manufacturer's instructions. RNA pellets were dissolved in 10-30 $\mu \mathrm{l}$ RNase- and DNase-free water, after which they were air-dried. The quantity and quality of total RNA were measured spectrophotometrically at 260 and $280 \mathrm{~nm}$ (NanoDrop 2000, Thermo Scientific). Isolated RNA was then stored at $-80^{\circ} \mathrm{C}$. Equal amounts of RNA were used for reverse transcription. Complementary DNA (cDNA) was synthesised from $1 \mu \mathrm{g}$ isolated RNA from each sample using the Transcriptor First Strand cDNA Synthesis Kit (Roche Diagnostics, Germany) according to the manufacturer's protocol, and synthesis reaction was carried out in an Eppendorf Mastercycler ep gradient S thermal cycler (Eppendorf, Hamburg, Germany). Samples were analysed in duplicates. cDNA products were kept at $-20^{\circ} \mathrm{C}$.

\section{Quantitative real-time PCR analysis}

Real-time polymerase chain reaction (PCR) was performed using a LightCycler 480 instrument (Roche Diagnostics, Mannheim, Germany) according to the manufacturer's instructions. The expression levels of the following genes were investigated: iNOS, COX-2 and VEGF. Beta actin was used as a housekeeping gene in order to normalise the mRNA expression levels of target genes. Probes and primers spanning the exon-exon junction were designed for each gene assay using the online UPL Assay Design Center (http://www.roche- 
applied-science.com/sis/rtpcr/upl/index.jsp). The sequences of the gene-specific primers and the UPL numbers are presented in Table 1. A 2- $\mu$ l volume of cDNA product was subjected to real-time PCR in a $10-\mu 1$ total reaction mixture containing $2.5 \mu \mathrm{l}$ of TaqMan Universal PCR Master Mix (Roche Diagnostics, Mannheim, Germany), $0.5 \mu 1$ of sense and antisense primers, and $0.1 \mu 1$ probe and template cDNA. Each sample was analysed in triplicate.

Table 1

Gene-specific primer and probe sequences

\begin{tabular}{lllr}
\hline Gene & \multicolumn{1}{c}{ Forward primer } & Reverse primer & $\begin{array}{r}\text { UPL } \\
\text { probe } \\
\text { no. }\end{array}$ \\
\hline ACTB & 5'-GATGTGGCTTCTTGGGTGTT-3' & 5'-CCAAGATAGGGACAGCTTGGT-3' & 43 \\
iNOS & 5'-TTTCTGGGAGCATCACTCCT-3' & 5'-AAGGGGACAGGACATAATTAACA-3' & 31 \\
COX-2 & 5'-TGCTTAAACAGGAGCATCCA-3' & 5'-TTAGCCTGCTCGTCTGGAAC-3' & 41 \\
VEGF & 5'-CGTGCCCACTGAGGAGTT-3' & 5'-GCCTTGATGAGGTTTGATCC-3' & 9 \\
\hline
\end{tabular}

\section{Statistical analysis}

The data were analysed using LightCycler Software v 3.5 (Roche Diagnostics). Relative mRNA expression of iNOS, COX-2 and VEGF were determined using Relative Expression Software Tool 2008 (REST ${ }^{\mathcal{O}}$ ) (Pfaffl et al., 2002). Correlations between the expression levels and the tumour grade were not determined because cycle threshold $(\mathrm{Ct})$ values obtained from real-time PCR analysis resulted in real-time gene expression levels, and each animal had a single Ct value.

\section{Results}

\section{Histopathological findings}

Twenty-nine malignant mammary tumours and six benign mammary tumours were diagnosed (Table 2 ). The commonest malignant tumour types in the study were carcinosarcoma $(8 / 29 ; 27.58 \%)$ and mixed carcinoma $(7 / 29 ; 24.13 \%)$. Clinically healthy mammary glands localised close to the gland with malignant tumour were evaluated and confirmed as non-neoplastic or healthy by histopathological evaluation. The maximum diameters of the malignant mammary tumours, histologic malignancy grades, tumour ulceration and necrosis, rate of growth and lymph node metastasis are presented in Table 3.

The determination of histologic malignancy grade of the 29 dogs with malignant mammary tumours revealed that 12 had $\mathrm{G}_{1}, 10$ had $\mathrm{G}_{2}$ and 7 had $\mathrm{G}_{3}$ tumours. Of the $13 \operatorname{dogs}\left(3\right.$ had $\mathrm{G}_{1}, 7$ had $\mathrm{G}_{2}$ and 3 had $\left.\mathrm{G}_{3}\right)$ in which histopathological lymph node examination was performed, lymph node metastasis was 
found in 1 dog with $G_{1}, 2 \operatorname{dogs}$ with $G_{2}$ and 1 dog with $G_{3}$. Tumour ulceration and necrosis were observed in 7 and 14 dogs, respectively (Table 3).

Table 2

\begin{tabular}{lc} 
Classification of canine mammary tumours (Goldschmidt et al., 201 \\
\hline Histological type & Number \\
\hline Malignant tumours & 29 \\
Carcinosarcoma & 8 \\
Mixed carcinoma & 7 \\
Solid carcinoma & 3 \\
Complex carcinoma & 2 \\
Intraductal papillary carcinoma & 2 \\
Tubulopapillary carcinoma & 2 \\
Carcinoma in situ & 1 \\
Squamous cell carcinoma & 1 \\
Tubular carcinoma & 1 \\
Spindle cell carcinoma & 1 \\
Comedocarcinoma & 1 \\
Benign tumours & 6 \\
Benign mixed tumour & 3 \\
Intraductal papillary adenoma & 1 \\
Simple adenoma & 1 \\
Adenomyoepithelioma & 1 \\
\hline
\end{tabular}

\section{Expression of iNOS, COX-2 and VEGF in canine mammary tumours}

The expression of iNOS, COX-2 and VEGF mRNA levels was significantly increased $(\mathrm{P}<0.05)$ in both benign and malignant tumours compared to adjacent non-neoplastic mammary glands (Fig. 1). In addition, the expressions were higher in malignant tumours than in benign tumours, although the difference was not statistically significant $(\mathrm{P}>0.05)$.

\section{Association of iNOS, COX-2 and VEGF expressions with clinicopathological parameters}

Table 3 presents the association between iNOS, COX-2 and VEGF expressions and clinicopathological features in malignant tumours. iNOS, COX-2 and VEGF expressions were associated with histological grade of malignancy and tumour growth rate $(P<0.05)$. The expressions of $\mathrm{G}_{1}$ tumours were not statistically different when compared to $\mathrm{G}_{2}(\mathrm{P}>0.05)$. On the other hand, the expression levels were higher in $\mathrm{G}_{3}$ tumours than in $\mathrm{G}_{1}$ tumours $(\mathrm{P}<0.05)$ (Fig. 2). There was no statistically significant association $(\mathrm{P}>0.05)$ between iNOS, COX-2 and VEGF mRNA expressions and tumour size (Fig. 3). 
Table 3

Association of clinicopathological features with iNOS, COX-2 and VEGF expression in malignant tumours

\begin{tabular}{|c|c|c|c|c|c|c|}
\hline \multirow{2}{*}{ Variable } & \multicolumn{2}{|c|}{ COX-2 } & \multicolumn{2}{|c|}{ VEGF } & \multicolumn{2}{|c|}{ iNOS } \\
\hline & $\mathrm{n}$ & $\mathrm{P}$ & $\mathrm{n}$ & $P$ & $\mathrm{n}$ & $\mathrm{P}$ \\
\hline \multicolumn{7}{|c|}{ Tumour size $(\mathrm{cm})$} \\
\hline $\mathrm{T}_{1}(<3 \mathrm{~cm})$ & 7 & & 11 & & 11 & \\
\hline $\mathrm{T}_{2}(3-5 \mathrm{~cm})$ & 11 & 0.271 & 11 & 0.214 & 11 & \\
\hline $\mathrm{T}_{3}(5 \mathrm{~cm})$ & 11 & 0.267 & 11 & 0.275 & 11 & 0.248 \\
\hline \multicolumn{7}{|c|}{ Differentiation grade } \\
\hline 1 & 8 & & 8 & & 8 & \\
\hline 2 & 8 & 0.165 & 8 & 0.105 & 8 & 0.172 \\
\hline 3 & 13 & 0.139 & 13 & 0.134 & 13 & 0.154 \\
\hline \multicolumn{7}{|c|}{ Histological grade of malignancy } \\
\hline Grade 1 & 12 & & 12 & & 12 & \\
\hline Grade 2 & 10 & $0.031^{*}$ & 10 & $0.044^{*}$ & 10 & $0.039^{*}$ \\
\hline Grade 3 & 7 & $0.036^{*}$ & 7 & $0.038^{*}$ & 7 & $0.023^{*}$ \\
\hline \multicolumn{7}{|l|}{ Ulceration } \\
\hline Present & 7 & & 7 & & 7 & \\
\hline Absent & 22 & 0.235 & 22 & 0.179 & 22 & 0.215 \\
\hline \multicolumn{7}{|l|}{ Necrosis } \\
\hline Present & 14 & & 14 & & 14 & \\
\hline Absent & 15 & 0.147 & 15 & 0.118 & 15 & 0.121 \\
\hline \multicolumn{7}{|c|}{ Lymph node metastasis } \\
\hline Present & 4 & & 4 & & 4 & \\
\hline Absent & 9 & 0.322 & 9 & 0.074 & 9 & 0.232 \\
\hline \multicolumn{7}{|l|}{ Rate of growth } \\
\hline Slow & 11 & & 11 & & 11 & \\
\hline Medium & 11 & $0.032^{*}$ & 11 & $0.028^{*}$ & 11 & $0.021 *$ \\
\hline Fast & 7 & $0.041^{*}$ & 7 & $0.036^{*}$ & 7 & 0.039 \\
\hline
\end{tabular}

Abbreviations: COX-2, cyclooxygenase-2; VEGF, vascular endothelial growth factor; iNOS, inducible nitric oxide synthases; ${ }^{*} \mathrm{P}<0.05$

\section{Discussion}

It has been reported that COX-2 level has prognostic significance and is increased in benign and malignant canine mammary tumours (Queiroga et al., 2010). In addition, it has been established that COX-2 expression is significantly higher in malignant than in benign tumours in dogs (Dore et al., 2003). However, COX-2 immunostaining was found to be altered in different histological types of benign tumours such as benign mixed tumours and tubular adenoma (Queiroga et 
al., 2007). In the study of Queiroga et al. (2007) the expression of COX-2 was shown in $96 \%$ of benign tumours and in $100 \%$ of the malignant tumours, whereas ductal hyperplasia did not express COX-2. Similarly, in our study COX-2 expression was higher in malignant tumours than in benign tumours, although the difference was not statistically significant. This study also demonstrated that COX-2 expression was higher in benign and malignant tumours than in adjacent non-neoplastic mammary glands.

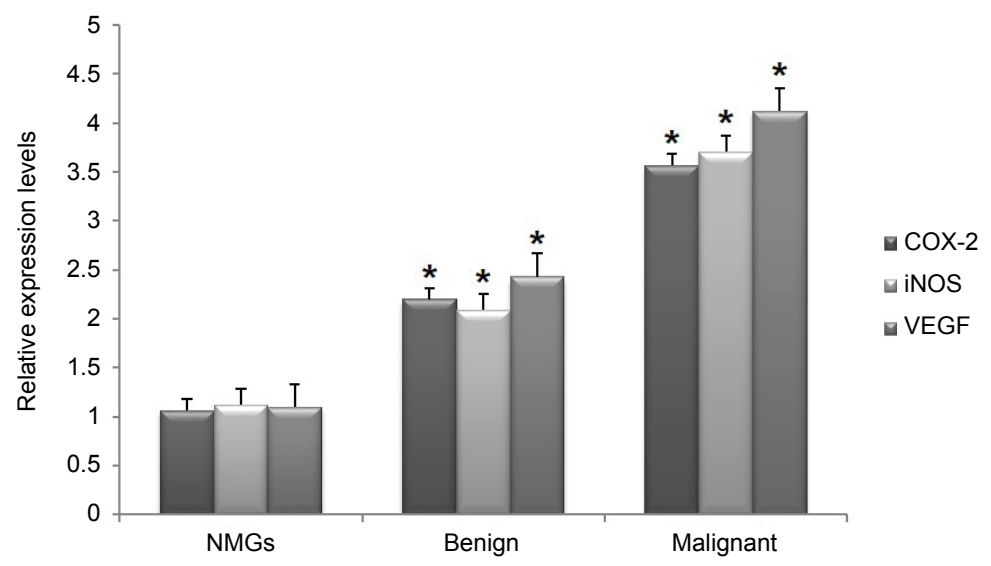

Fig. 1. Quantitative real-time PCR results showing COX-2, iNOS and VEGF mRNA expression levels in canine mammary tissue. Bars represent expression levels normalised to beta actin as the housekeeping gene and relative to non-neoplastic mammary glands (NMGs). ${ }^{*} \mathrm{P}<0.05$ relative to the NMGs group; mRNA: messenger RNA; PCR: polymerase chain reaction

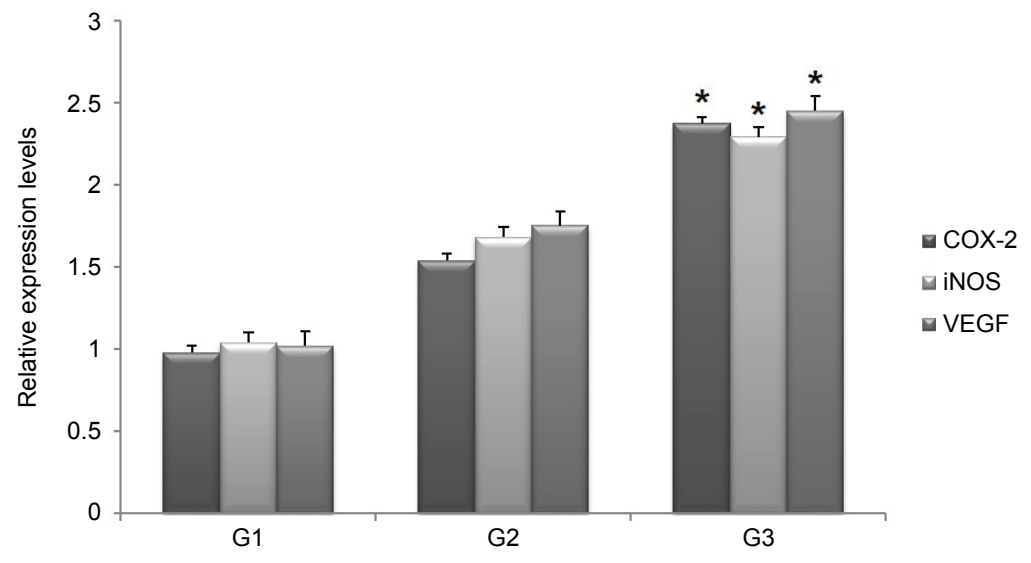

Fig. 2. Quantitative real-time PCR results showing COX-2, iNOS and VEGF mRNA expression levels of histological malignancy in canine mammary tissue. Bars represent expression levels normalised to beta actin as the housekeeping gene and relative to $\mathrm{G} 1$ group. ${ }^{*} \mathrm{P}<0.05$ relative to the G1 group. mRNA: messenger RNA; PCR: polymerase chain reaction; Grade 1 (G1), well differentiated; Grade 2 (G2), moderately differentiated; Grade $3(\mathrm{G} 3)$, poorly differentiated tumours 


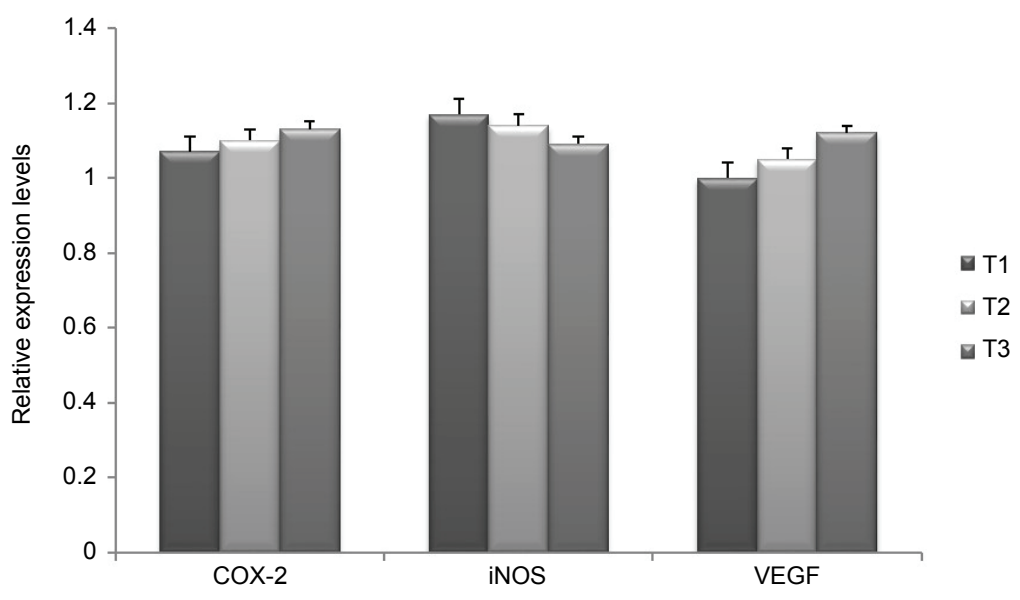

Fig. 3. Quantitative real-time PCR results showing COX-2, iNOS and VEGF mRNA expression levels of tumour size in canine mammary tissue. Bars represent expression levels normalised to beta actin as the housekeeping gene and relative to the T1 group. mRNA: messenger RNA; PCR: polymerase chain reaction

COX-2 overexpression in human breast cancer and its relation to the presence of distant metastasis and poor prognosis have been reported previously (Denkert et al., 2003). In canine mammary tumours, it has been revealed that COX-2 level is associated with larger tumour size, skin ulceration, adhesion to skin and underlying tissue, and more aggressive histological types (Queiroga et al., 2005; Guimaraes et al., 2014). In the present study, COX-2 expression was higher in poorly differentiated than in well-differentiated tumours, suggesting that its higher expression might be related to the increased aggressiveness of malignant tumours.

It has been reported that COX-2 may be associated with angiogenesis because of the reduced adhesion of tumour cells to the extracellular matrix, angiogenesis and progress of metastasis in human breast cancer (Costa et al., 2002). Several studies have shown that overexpression of COX-2 in tumour tissue is correlated with VEGF expression and microvessel density, and is a factor involved in the aggressiveness of canine malignant mammary tumours (Heller et al., 2005; Queiroga et al., 2011). The present study has confirmed the results of Queiroga et al. (2011) that COX-2 and VEGF may be related to the increased aggressiveness of malignant tumours. The histological tumour grade is associated with the prognosis, whereas high-grade tumours are connected with low overall survival time in canine mammary carcinoma (Perez Alenza et al., 1997; Karayannopoulou et al., 2005). Our study has revealed that the histological grade is related to the expression of iNOS, COX-2 and VEGF.

Tascene et al. (2012) reported that serum nitric oxide level in dogs with mammary tumours is significantly higher than in healthy dogs. Recent studies 
have shown that iNOS expression in human colorectal and gallbladder cancer is associated with increased disease-specific fatality and/or malignancy degree (Niu et al., 2004; Zafirellis et al., 2010). Moreover, it has also been determined that iNOS expression is related to different stages of human breast carcinoma (Ranganathan et al., 2016). Our study is the first to determine the expression of iNOS by qRT-PCR analysis in malignant mammary tumours in dogs, and the findings of this work show that the expression of iNOS depends on tumour grade.

Perez Alenza et al. (1997) reported that dogs with larger tumours had short disease-free survival (DFS) and overall survival (OS). In addition, Philibert et al. (2003) found a significant difference in survival time depending on the size of canine mammary tumours, and dogs with tumours larger than $3 \mathrm{~cm}$ had a significantly shorter survival than dogs with tumours smaller than $3 \mathrm{~cm}$. Additionally, Ferreira et al. (2009) revealed that larger tumours were mostly malignant and survival time was shorter in female dogs. It is known that increase in tumour size is not only associated with malignancy but also with metastasis to lymph nodes (Sorenmo et al., 2000). Moreover, Queiroga et al. (2011) reported that tumour size was not associated with COX-2 and VEGF expression in canine malignant mammary tumours. Similarly, there was no statistically significant association between iNOS, COX-2 and VEGF mRNA expression levels and tumour size in our study.

Karayannopoulou et al. (2005) found that the predictive value of histological grading of canine mammary carcinomas was associated with prognosis and that histological grading might be useful in managing post-surgical treatment. The results of our study revealed that iNOS, COX-2 and VEGF are overexpressed in canine mammary tumours compared to adjacent non-neoplastic mammary glands, and this may contribute to the increased aggressiveness of malignant tumours.

In conclusion, the higher expression of iNOS, COX-2 and VEGF mRNA levels in malignant tumours and the tendency of increase in these levels (particularly in grade 3 tumours) suggest that these parameters are involved in inducing aggressiveness in canine mammary tumours.

\section{References}

Bing, R. J., Miyataka, M., Rich, K. A., Hanson, N., Wang, X., Slosser, H. D. and Shi, S. R. (2001): Nitric oxide, prostanoids, cyclooxygenase, and angiogenesis in colon and breast cancer. Clin. Canc. Res. 7, 3385-3392.

Cianfrocca, M. and Goldstein, L. J. (2004): Prognostic and predictive factors in early-stage breast cancer. Oncologist 9, 606-616.

Costa, C., Soares, R., Reis-Filho, J. S., Leitaõ, D., Amendoeira, I. and Schmitt, F. C. (2002): Cyclo-oxygenase 2 expression is associated with angiogenesis and lymph node metastasis in human breast cancer. J. Clin. Pathol. 55, 429-434. 
Denkert, C., Winzer, K. J., Müller, B. M., Weichert, W., Pest, S., Kobel, M., Kristiansen, G., Reles, A., Siegert, A., Guski, H. and Hauptmann, S. (2003): Elevated expression of cyclooxygenase-2 is a negative prognostic factor for disease free survival and overall survival in patients with breast carcinoma. Cancer 97, 2978-2987.

Dore, M., Lanthier, I. and Sirois, J. (2003): Cyclooxygenase-2 expression in canine mammary tumours. Vet. Pathol. 40, 207-212.

Elston, C. W. and Ellis, I. O. (1998): Assessment of histological grade. In: Elston, C. W. and Ellis, I. O. (eds) The Breast. Vol. 13. Churchill Livingstone, Edinburgh. pp. 356-384.

Ferreira, E., Bertagnolli, A. C., Cavalcanti, M. F., Schmitt, F. C. and Cassali, G. D. (2009): The relationship between tumour size and expression of prognostic markers in benign and malignant canine mammary tumours. Vet. Comp. Oncol. 7, 230-235.

Förstermann, U., Closs, E. I., Pollock, J. S., Nakane, M., Schwarz, P., Gath, I. and Kleinert, H. (1994): Nitric oxide synthase isozymes. Characterization, purification, molecular cloning, and functions. Hypertension 23, 1121-1131.

Goldschmidt, M., Peña, L., Rasotto, R. and Zappulli, V. (2011): Classification and grading of canine mammary tumors. Vet. Pathol. 48, 117-131.

Guimaraes, M. J., Carvalho, M. I., Pires, I., Prada, J., Gonzalez, Gil A., Lopes, C. and Queiroga, F. L. (2014): Concurrent expression of cyclo-oxygenase-2 and epidermal growth factor receptor in canine malignant mammary tumours. J. Comp. Path. 150, 27-34.

Heller, D. A., Clifford, C. A., Goldschmidt, M. H., Holt, D. E., Shofer, F. S., Smith, A. and Sorenmo, K. U. (2005): Cyclooxygenase-2 expression is associated with histologic tumour type in canine mammary carcinoma. Vet. Pathol. 42, 776-780.

Howe, L. R. (2007): Cyclooxygenase/prostaglandin signaling and breast cancer. Breast Cancer Res. 9, 210.

Islam, M. S., Matsumoto, M., Hidaka, R., Miyoshi, N. and Yasuda, N. (2012): Expression of NOS and VEGF in feline mammary tumours and their correlation with angiogenesis. Vet. J. 192, $338-344$.

Johnston, S. D., Kustritz, M. V. R. and Olson, P. N. S. (2001): Canine and Feline Theriogenology. W. B. Saunders, Philadelphia.

Karayannopoulou, M., Kaldrymidou, E., Constantinidis, T. C. and Dessiris, A. (2005): Histological grading and prognosis in dogs with mammary carcinomas: Application of a human grading method. J. Comp. Path. 133, 246-252.

Knowles, R. G. and Moncada, S. (1994): Nitric oxide synthases in mammals. Biochem. J. 298, 249-258.

Lala, P. K. and Chakraborty, C. (2001): Role of nitric oxide in carcinogenesis and tumour progression. Lancet. Oncol. 3, 149-156.

Lechner, M., Lirk, P. and Rieder, J. (2005): Inducible nitric oxide synthase (iNOS) in tumor biology: The two sides of the same coin. Semin. Cancer Biol. 15, 277-289.

Millanta, F., Citi, S., Della Santa, D., Porciani, M. and Poli, A. (2006): COX-2 expression in canine and feline invasive mammary carcinomas: correlation with clinicopathological features and prognostic molecular markers. Breast Canc. Res. Treat. 98, 115-120.

Moulton, J. E. (1990): Tumors of the skin and soft tissues. In: Moulton, J. E. (ed.) Tumors in Domestic Animals. Third edition. University of California Press, Los Angeles, CA. p. 23.

Niu, X. J., Wang, Z. R., Wu, S. L., Geng, Z. M., Zhang, Y. F. and Qing, X. L. (2004): Relationship between inducible nitric oxide synthase expression and angiogenesis in primary gallbladder carcinoma tissue. World J. Gastroenterol. 10, 725-728.

Owen, L. N. (1980): TNM Classification of Tumours in Domestic Animals. First edition. World Health Organization, Geneva. pp. 2-53.

Perez Alenza, M. D., Pena, L., Nieto, A. I. and Castano, M. (1997): Clinical and pathological prognostic factors in canine mammary tumors. Ann. Ist. Super Sanita. 33, 581-585. 
Pfaffl, M. W., Horgan, G. W. and Dempfle, L. (2002): Relative expression software tool (REST) for groupwise comparison and statistical analysis of relative expression results in real-time PCR. Nucl. Acids Res. 30, e36.

Philibert, J. C., Snyder, P. W., Glickman, N., Glickman, L. T., Knapp, D. W. and Waters, D. J. (2003): Influence of host factors on survival in dogs with malignant mammary gland tumors. J. Vet. Int. Med. 17, 102-106.

Queiroga, F. L., Alves, A., Pires, I. and Lopes, C. (2007): Expression of COX-1 and COX-2 in canine mammary tumours. J. Comp. Path. 136, 177-185.

Queiroga, F. L., Perez-Alenza, M. D., Silvan, G., Peña, L., Lopes, C. and Illera, J. C. (2005): COX2 levels in canine mammary tumors, including inflammatory mammary carcinoma: clinicopathological features and prognostic significance. Anticanc. Res. 25, 4269-4276.

Queiroga, F. L., Pires, I., Lobo, L. and Lopes, C. S. (2010): The role of COX-2 expression in the prognosis of dogs with malignant mammary tumours. Res. Vet. Sci. 88, 441-445.

Queiroga, F. L., Pires, I., Parente, M., Gregório, H. and Lopes, C. S. (2011): COX-2 overexpression correlates with VEGF and tumour angiogenesis in canine mammary cancer. Vet. J. 189, 77-82.

Ranganathan, S., Krishnan, A. and Sivasithambaram, N. D. (2016): Significance of twist and iNOS expression in human breast carcinoma. Mol. Cell. Biochem. 412, 41-47.

Restucci, B., Papparella, S., Maiolino, P. and De Vico, G. (2002): Expression of vascular endothelial growth factor in canine mammary tumors. Vet. Pathol. 39, 488-493.

Simpson, J. F., Gray, R., Dressler, L. G., Cobau, C. D., Falkson, C. I., Gilchrist, K. W., Pandya, K. J., Page, D. L. and Robert, N. J. (2000): Prognostic value of histologic grade and proliferative activity in axillary node-positive breast cancer: results from the Eastern Cooperative Oncology Group Companion Study, EST 4189. J. Clin. Oncol. 18, 2059-2069.

Sorenmo, K. J., Shofer, F. S. and Goldschmidt, M. H. (2000): Effect of spaying and timing of spaying on survival of dogs with mammary carcinoma. J. Vet. Intern. Med. 14, 266-270.

Tascene, N., Kismali, G., Vural, S., Karagul, H. and Sel, T. (2012): Serum neopterin, sialic acid and nitric oxide levels in dogs with malignant mammary tumours. Vet. Comp. Oncol. 10, $155-159$.

Thomsen, L. L., Miles, D. W., Happerfield, L., Bobrow, L. G., Knowles, R. G. and Moncada, S. (1995): Nitric oxide synthase activity in human breast cancer. Br. J. Cancer 72, 41-44.

Vakkala, M., Kahlos, K., Lakari, E., Paakko, P., Kinnula, V. and Soini, Y. (2000): Inducible nitric oxide synthase expression, apoptosis, and angiogenesis in in situ and invasive breast carcinomas. Clin. Cancer Res. 6, 2408-2416.

Villalobos, A. and Kaplan, L. (2007): Canine and Feline Geriatric Oncology: Honoring the Human-Animal Bond. First edition. Wiley-Blackwell, Iowa. pp. 3-23.

Williams, C. S., Mann, M. and DuBois, R. N. (1999): The role of cyclooxygenases in inflammation, cancer, and development. Oncogene 18, 7908-7916.

Zafirellis, K., Zachaki, A., Agrogiannis, G. and Gravani, K. (2010): Inducible nitric oxide synthase expression and its prognostic significance in colorectal cancer. APMIS 118, 115-124. 